\title{
ОСОБЕННОСТИ ВОЗДУШНОЙ ПРОВОДИМОСТИ ЗВУКОВ У СТУДЕНТОВ В РЕЗУЛЬТАТЕ ВОЗДЕЙСТВИЯ УЧЕБНОЙ И ФИЗИЧЕСКОЙ НАГРУЗКИ
}

\author{
Морякина Светлана Васильевна \\ К.б.н., дочент, ФГБОУ ВО «Чеченский \\ государственный университет» \\ s.moriakina@yandex.ru \\ Анзоров Ваха Асхадович
}

FEATURES OF AIR CONDUCTIVITY OF SOUNDS IN STUDENTS AS A RESULT OF IMPACT OF TRAINING AND PHYSICAL ACTIVITY

S. Moryakina

V. Anzorov

Summary. Scientific article is devoted to the study of air conductivity of sound signals in students of the Chechen Republic of different sex as a result of the impact of educational and dosed physical activity. During the examination of female students of all courses and second-year students, we found a reduction in hearing acuity for air conduction. Fourth-year students had a non-ordinary response to the learning burden. Their right ear audible threshold was lower than their left ear. In fifth-year students, the experiment showed the presence of an unstable wavy character with some improvement in the conductivity of sounds for the right ear. Auditory sensitivity was higher, with senior fifth year students and fourth year students. We did not find the presence of deafness in all the examined groups of students and female students. After physical exercise, the conductivity of sounds deteriorated, the audibility threshold increased, especially at low frequencies in young men.

Keywords: students, air conduction of sounds, learning and physical activity, gender signs.

\section{Введение}

дной из наиболее актуальных проблем современной молодежи является снижение слухового восприятия, и именно студенческая молодежь в наши дни составляет большую группу риска по тугоухости. А как известно, слух для человека является биологическим и социальным фактором речевого общения.
Речевые сигналы ограничены частотным диапазоном от 1000 до 10000 Гц и интенсивностью от 50 до 80 дБ $[5]$.

Для исследования воздушной звукопроводимости используют аудиометрические методы, основанные на принципе «нервной аудиометрии», которые впервые были применены в 1947 году Beresy [7]. 
Таблица 1. Сопоставление остроты слуха при воздушной проводимости у девушек всех курсов

\begin{tabular}{|c|c|c|c|c|c|c|}
\hline \multirow{3}{*}{$\begin{array}{l}\text { Частота } \\
\text { в Гц }\end{array}$} & \multicolumn{6}{|c|}{ Слуховые пороги, дБ (М \pm m) } \\
\hline & \multicolumn{2}{|c|}{ Второй курс } & \multicolumn{2}{|l|}{ Четвертый курс } & \multicolumn{2}{|l|}{ Пятый курс } \\
\hline & Левое ухо (AS) & Правое ухо (AD) & Левое ухо (AS) & Правое ухо (AD) & Левое ухо (AS) & Правое ухо (AD) \\
\hline 125 & $13,43 \pm 7,899$ & $17,81 \pm 9,656$ & $12,17 \pm 8,094$ & $19,34 \pm 9,451$ & $11,05 \pm 6,142$ & $11,05 \pm 8,592^{*}$ \\
\hline 250 & $16,25 \pm 8,660$ & $20,00 \pm 8,165$ & $18,26 \pm 8,476$ & $24,34 \pm 11,412$ & $13,68 \pm 8,635$ & $17,63 \pm 6,534$ \\
\hline 500 & $19,37 \pm 9,639$ & $20,31 \pm 8,845$ & $17,82 \pm 9,750$ & $23,04 \pm 11,154$ & $16,05 \pm 9,366$ & $20,78 \pm 9,997$ \\
\hline 750 & $14,37 \pm 7,932$ & $18,75 \pm 8,66$ & $15,43 \pm 8,649$ & $19,13 \pm 16,001$ & $15,52 \pm 8,803$ & $16,31 \pm 10,651$ \\
\hline 1000 & $14,37 \pm 8,732$ & $21,87 \pm 17,877$ & $15,65 \pm 11,804$ & $17,60 \pm 9,998$ & $16,57 \pm 9,726$ & $17,85 \pm 13,876$ \\
\hline 1500 & $11,87 \pm 8,342$ & $17,5 \pm 11,255$ & $14,13 \pm 9,960$ & $17,82 \pm 11,854$ & $10,52 \pm 7,434$ & $14,47 \pm 7,618$ \\
\hline 2000 & $9,37 \pm 7,27$ & $12,18 \pm 7,521$ & $8,91 \pm 7,223$ & $11,30 \pm 8,008$ & $7,97 \pm 6,21$ & $8,94 \pm 7,92$ \\
\hline 3000 & $7,18 \pm 6,316$ & $9,06 \pm 6,884$ & $6,52 \pm 6,112$ & $10,00 \pm 10,000$ & $3,68 \pm 4,667$ & $3,68 \pm 4,956^{* *}$ \\
\hline 4000 & $5,31 \pm 5,313$ & $9,68 \pm 9,031$ & $8,09 \pm 6,978$ & $10,87 \pm 8,209$ & $5,78 \pm 4,171$ & $4,21 \pm 5,073^{*}$ \\
\hline 6000 & $10,62 \pm 6,292$ & $12,81 \pm 8,938$ & $14,56 \pm 11,069$ & $16,30 \pm 17,335$ & $7,89 \pm 7,965$ & $9,47 \pm 9,985$ \\
\hline 8000 & $13,43 \pm 7,004$ & $15,31 \pm 9,911$ & $15,21 \pm 12,011$ & $20,21 \pm 15,846$ & $12,10 \pm 10,582$ & $11,84 \pm 9,008$ \\
\hline
\end{tabular}

Примечание: *P $<0,05 ; * * 0,02$

Таблица 2. Сопоставление остроты слуха при воздушной проводимости у юношей всех курсов

\begin{tabular}{|c|c|c|c|c|c|c|}
\hline \multirow{3}{*}{$\begin{array}{l}\text { Частота } \\
\text { в Гц }\end{array}$} & \multicolumn{6}{|c|}{ Слуховые пороги, дБ (M $\pm \mathrm{m})$} \\
\hline & \multicolumn{2}{|c|}{ Второй курс } & \multicolumn{2}{|l|}{ Четвертый курс } & \multicolumn{2}{|l|}{ Пятый курс } \\
\hline & Левое ухо (AS) & Правое ухо (AD) & Левое ухо (AS) & Правое ухо (AD) & Левое ухо (AS) & Правое ухо (AD) \\
\hline 125 & $11,66 \pm 2,887$ & $16,66 \pm 10,408$ & $12,85 \pm 8,092$ & $6,42 \pm 3,780^{*}$ & $11,66 \pm 7,638$ & $11,25 \pm 6,292$ \\
\hline 250 & $10,00 \pm 5,000$ & $21,66 \pm 7,638$ & $14,28 \pm 9,759$ & $13,57 \pm 6,268$ & $13,33 \pm 5,774$ & $16,66 \pm 2,887$ \\
\hline 500 & $11,66 \pm 2,882$ & $25,00 \pm 10,000$ & $17,85 \pm 7,559$ & $12,14 \pm 7,559^{*}$ & $13,33 \pm 5,774$ & $18,33 \pm 17,559$ \\
\hline 750 & $13,33 \pm 5,774$ & $21,66 \pm 7,638$ & $10,71 \pm 8,864$ & $7,85 \pm 4,880^{* * *}$ & $20,00 \pm 5,000$ & $11,66 \pm 12,583$ \\
\hline 1000 & $8,33 \pm 7,638$ & $15,00 \pm 5,000$ & $12,14 \pm 5,669$ & $7,14 \pm 5,669$ & $16,66 \pm 5,774$ & $18,33 \pm 2,887$ \\
\hline 1500 & $6,66 \pm 7,638$ & $10,00 \pm 5,000$ & $9,28 \pm 4,499$ & $3,57 \pm 4,756$ & $15,00 \pm 5,000$ & $13,33 \pm 5,774$ \\
\hline 2000 & $5,00 \pm 5,000$ & $8,33 \pm 2,887$ & $7,14 \pm 5,669$ & $5,00 \pm 5,000$ & $16,66 \pm 10,408$ & $11,66 \pm 10,408$ \\
\hline 3000 & $10,00 \pm 8,660$ & $5,00 \pm 5,000$ & $9,28 \pm 8,381$ & $6,42 \pm 4,756$ & $15,00 \pm 8,660$ & $3,33 \pm 2,887$ \\
\hline 4000 & $13,33 \pm 18,930$ & $13,33 \pm 11,54$ & $7,14 \pm 4,880$ & $9,28 \pm 6,726$ & $8,33 \pm 10,408$ & $6,66 \pm 2,887$ \\
\hline 6000 & $10,00 \pm 5,000$ & $6,66 \pm 2,887$ & $5,00 \pm 4,082$ & $6,42 \pm 6,268$ & $10,00 \pm 10,00$ & $6,66 \pm 11,547$ \\
\hline 8000 & $6,66 \pm 2,887$ & $20,00 \pm 5,000$ & $14,28 \pm 7,868$ & $12,14 \pm 3,934^{* *}$ & $11,66 \pm 12,583$ & $16,66 \pm 16,073$ \\
\hline
\end{tabular}

Примечание: *P $<0,05 ;{ }^{* *} \mathrm{P}<0,02 ;{ }^{* * *} \mathrm{P}<0,001$

Как известно из литературных источников, чрезмерная умственная и физическая нагрузка могут оказывать неблагоприятное влияние на функциональное состояние слухового анализатора [10].

Поэтому проведенные нами исследования с целью установления изменений остроты слуха при учебной и дозированной физической нагрузке у разнополых студентов носят весьма актуальный характер.

В более ранних публикациях мы уже затрагивали тему воздействия физических нагрузок на слуховую чувствительность студентов [4].

\section{Материал и метолы исслеАований}

Участниками эксперимента стали 72 студента биолого-химическом факультете Чеченского государственно- го университета (из них 57 девушек и 15 юношей) 2-го, 4-го, и 5-го курсов, которые составили три группы. В каждой группе были выделены две подгруппы по гендерным признакам.

Исследовательский материал был собран в лаборатории «Физиология человека» с октября по декабрь 2019 года.

\section{Было проведено четыре серии экспериментов.}

Серия 1. Анализ воздушной проводимости слухового анализатора у юношей и девушек путем сопоставления данных слуховой проводимости левого и правого уха.

Серия 2. Сопоставление показателей остроты слуха отдельно у девушек и юношей всех курсов. Установление уровня снижения воздушной проводимости звука. 
Проверка версии о некотором преобладании слуховой чувствительности у мужчин.

Серия 3. Установление степеней тугоухости у студентов и студенток разных курсов, основанной на усредненных значениях порогов звуковосприятия на частотах 0,5 ; $1 ; 2$ и 4 кГц.

Серия 4. Анализ реакции слуховой системы при воздушной проводимости на дозированную физическую нагрузку в виде пробы Мартине (20 приседаний за одну минуту для девушек и 30 - для юношей). В эксперименте участвовали: 21 девушка и 7 юношей четвертого курса.

У студентов определяли остроту слуха при воздушной проводимости по окончании учебных занятий. Для воздушной проводимости звука использовались следующие частоты: 125, 250, 500, 750, 1000, 1500, 2000, 3000, $4000,6000,8000$ Гц.

Для воздушной проводимости звука при физической нагрузке использовались следующие частоты: 125, 500, 2000, 4000, 6000 Гц.

Остроту слуха исследовали с помощью автоматизированного аудиометра АА-02.

Для статистической обработки использовалась программа «Excel 2016».

\section{Результаты исслеАований и обсу» $\triangle$ ение}

В первой серии экспериментов мы проанализировали данные воздушной проводимости слухового анализатора у испытуемых 2, 4 и 5 курсов (табл. 1,2).

Мы обратили внимание, что у девушек второго курса порог остроты слуха правого уха повышен в среднем на $32,5 \%$ при исследовании всех частот от 125 до 8000 Гц.

Самая высокая острота слуха была зафиксирована для двух средних частот -2000 и 3000 герц, а также для высокочастотной - 4000 герц, особенно для левого уха (ниже 10 дБ).

У юношей второго курса мы установили такую же зависимость, как и у девушек, которая заключалась в том, что слышимость левого уха была в среднем выше на 87,8\% (это гораздо выше, чем у девушек второго курса - 32,5\%), чем правого, кроме частот 3000 и 6000 Гц, где острота слуха была выше у левого уха.

Сравнивая данные порога слышимости правого и левого уха у студенток четвертого курса нами установле- ны такие же изменения, как и у студенток второго курса. То есть для правого уха было отмечено ухудшение слышимости в среднем на 30\%, чем для левого. Наилучшая слышимость была отмечена для частот 2000, 3000 и 4000 герц.

Что касается студентов четвертого курса, то у них мы наблюдали обратную зависимость. Острота слуха правого уха у них оказалась лучше, чем левого на 32,5\%, кроме высокочастотных тонов 4000 и 6000 герц. Причем правое ухо у этой группы студентов практически на всех исследуемых частотах обладало хорошим слухом на уровне до 10 дБ.

Студентки пятого курса имели такую же однотипную реакцию, как и девушки второго и четвертого курсов. Правое ухо отличалось более высоким порогом слышимости в среднем на 18,6\%. Исключение составляли высокочастотные тоны звука на уровне 4000 и 8000 герц, где острота слуха была лучше для левого уха. Наибольшая слуховая чувствительность как правого, так и левого уха была установлена от 2000 до 6000 герц.

У студентов пятого курса эксперимент показал наличие нестабильного волнообразного характера с некоторым улучшением проводимости звуков для правого уха.

Во второй серии экспериментов мы сопоставили показатели остроты слуха по воздушной проводимости отдельно у девушек и юношей всех курсов.

В результате было установлено, что слуховая чувствительность оказалась выше, у студенток старшего пятого курса и у студентов четвертого курса. Возможно, это связано с адаптацией к учебным нагрузкам [3].

Кроме того, мы обнаружили критический уровень снижения слуха (ниже 20 дБ) у студенток и студентов второго курса (девушки - частоты 500 и 1000 герц; юноши - частоты 250, 500 и 750 герц) и студенток четвертого курса (частоты 250 и 500 герц) на уровне средних частот для правого уха.

В данном случае речь идет о нарушении звукопроводящей системы, вызванной повреждением наружного или среднего уха. Снижение слуха в низкочастотном диапазоне может наблюдается при перенесенных простудных заболеваниях.

Существует мнение о некотором преобладании слуховой чувствительности у мужчин.

Мы также проверили эту версию, которая нашла некоторое подтверждение (левое ухо) в наших экспериментах для второго курса. 


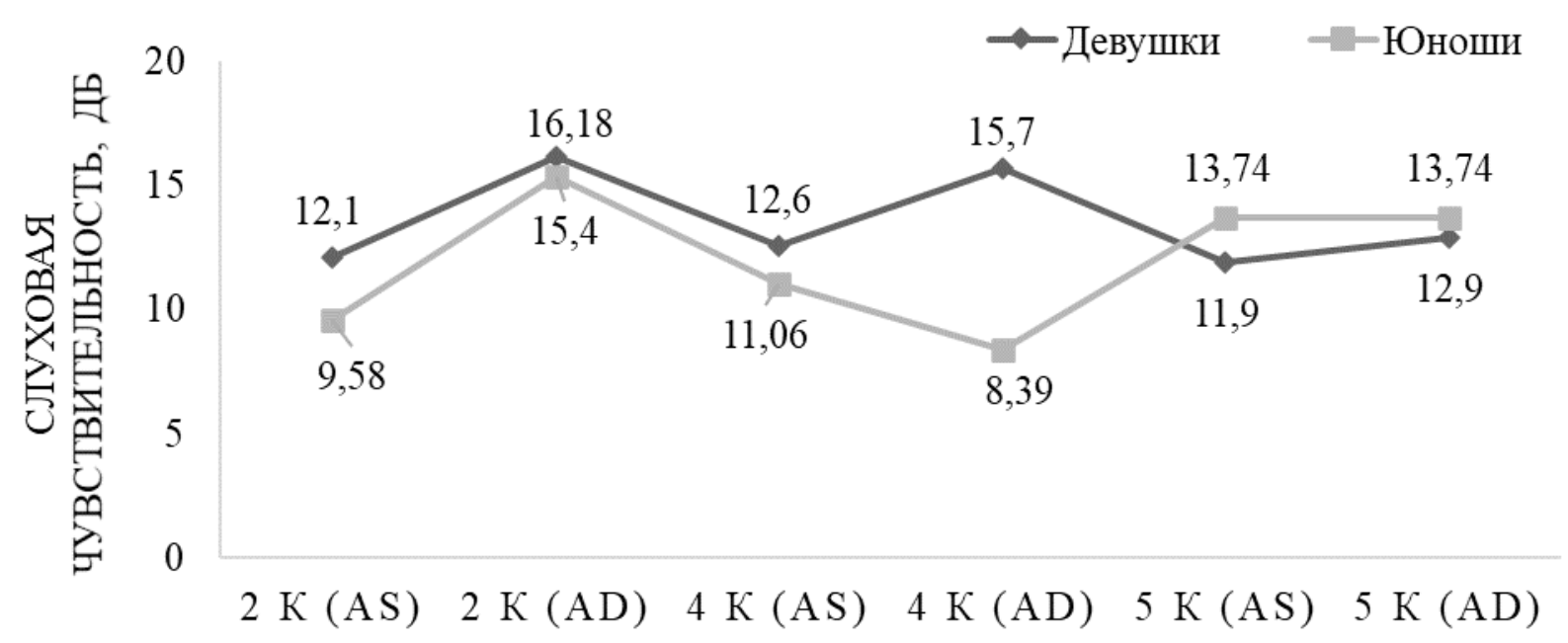

Рис. 1. Анализ возможного наличия тугоухости у девушек и юношей всех курсов

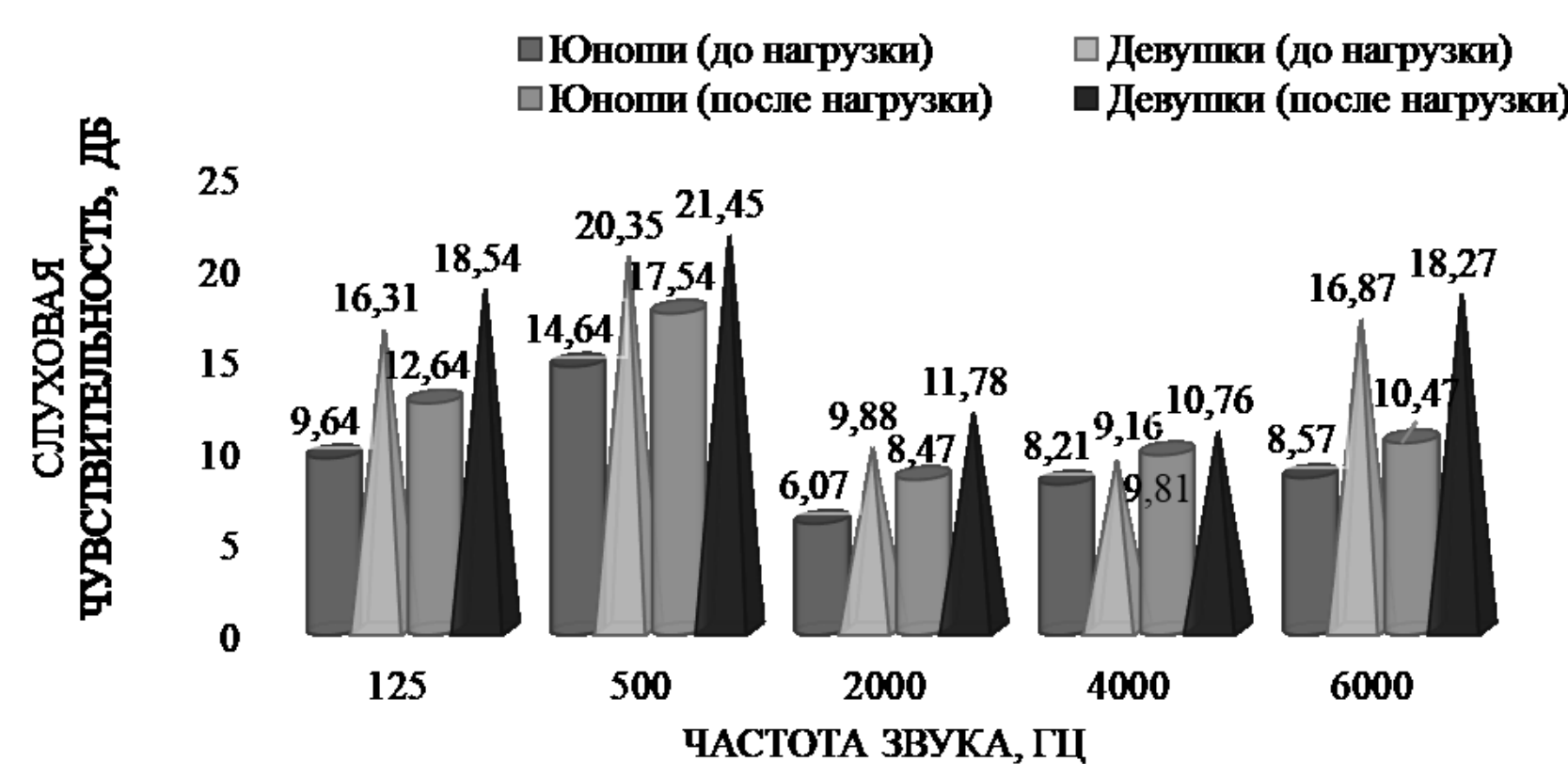

Рис. 2. Динамика порога слышимости слухового анализатора у студентов и студенток при воздушной проводимости до и после физической нагрузки

Но показатели остроты слуха у девушек и юношей носили не стабильный характер для разных частот.

Для четвертого курса проверяемая нами теория полностью подтвердилась.

Острота слуха у юношей этой группы действительно была выше, чем у девушек для всех исследуемых частот.
Для пятого курса проверяемая нами теория не подтвердилась.

В третьей серии экспериментов мы провели анализ возможного наличия тугоухости с помощью международной классификации степеней тугоухости, основанной на усредненных значениях порогов звуковосприятия на частотах 500; 1000; 2000 и 4000 Гц [2]. 
После проведенных вычислений, которые представлены на рис. 1 наличие тугоухости во всех обследованных группах студентов и студенток мы не обнаружили.

В четвертой серии экспериментов мы решили проверить, как будет реагировать слуховой анализатор на дозированную физическую нагрузку в виде пробы Мартине.

Был проведен анализ данных воздушной проводимости звука для разных частот (низкие, средние и высокие) до и после выполнения нагрузки. За основу брался усредненный показатель остроты слуха для обоих ушей.

При подаче звука разной частоты мы обратили внимание, что у испытуемых юношей и девушек после выполнения физической нагрузки, происходит ухудшение проводимости звуков, повышается порог слышимости, особенно на низких частотах (125 и 500 герц) у юношей (рис. 2).

\section{Зак^ючение}

При обследовании студенток всех курсов и студентов второго курса нами было установлено однотипное снижение проводимости и чувствительности рецепторного ап- парата правого уха с более выраженным сдвигом у юношей, которое проявлялось в снижении остроты слуха.

Обычно ведущее ухо правое, при этом доминирует левое полушарие. На ведущие органы обычно приходится большая нагрузка и они быстрее утомляются [9]. В результате снижаются их функции, что характерно для наших исследований.

У студентов четвертого курса нами была установлена не ординарная реакция на учебную нагрузку. Порог слышимости правого уха у них был ниже, чем левого. Следовательно, левое ухо у этой группы студентов было подвержено утомлению в большей степени. Возможно, у этих студентов доминирует правое полушарие и соответственно левое ухо является ведущим [8].

Наличие тугоухости во всех обследованных группах студентов и студенток мы не обнаружили.

Также было обнаружено, что, дозированная физическая нагрузка снижает проводимость и ухудшает порог чувствительности и возбудимости рецепторного аппарата слухового анализатора. Этот факт можно объяснить снижением функциональной подвижности слуховых зон коры $[1,6]$.

\section{ЛИТЕРАТУРА}

1. Баданов А. В. Влияние учебной нагрузки на умственное и физическое состояние студентов // Вестник Бурятского государственного университета. 2011. № 13. C. 12-15.

2. Загорянская М.Е., Румянцева М. Г., Дайняк Л. Б. Возможности профилактики развития тугоухости и глухоты на основе системного анализа данных эпидемиологии нарушения слуха // 7 съезд оторинолар. России: Тез докл. СПб., 2006. С. $25-26$.

3. Зубкова Ю. А. Гендерные особенности нарушения работы слухового анализатора лиц трудоспособного возраста // Материалы IX Международной студенческой научной конференции «Студенческий научный форум 2017» URL: https://scienceforum.ru/2017/article/2017035332.

4. Морякина С.В., Анзоров В.А., Солтагериева М. И., Мирзоева Х. У. Особенности слуховой чувствительности у студентов в зависимости от степени физической нагрузки // Сборник статей Международной научно-практической конференции «Фундаментальная и прикладная наука: состояние и тенденции развития». 08 сентября 2019 г. Петрозаводск: МЦНП «Новая наука», 2019. С. 197-204.

5. Оториноларингология: учебник / Под ред. И. Б. Солдатова, В. Р. Гофмана. СПб: ЭЛБИ, 2000.

6. Ратнер М.В., Зверева Г.С. Функциональное состояние слухового анализатора при совместном воздействии шума, вибрации, физической работы и высокой температуры // Гигиена труда и проф. заболевания. М., 1982. № 7. С. 47-50.

7. Современные научные исследования и инновации. 2012. № 4. URL: http://web.snauka.ru/issues/2012/04/11029.

8. Терютин Ф.М., Барашков Н. А., Федотова Э. Е. Аудиологический анализ состояния слуха в случайной выборке лиц молодого возраста // Российская оториноларингология. 2012. № 4 (59). С. 101-110.

9. Новикова Е.И., Надежкина Е. Ю., Ситяева С. М., Новиков Д. С. Физиология сенсорных систем: учебно-методическое пособие. Волгоград: Волгоградский государственный социально-педагогический университет, «Перемена», 2015. 92 с.

10. Янкевич И. Е. Динамика адаптационных процессов к физическим нагрузкам слабослышащих подростков под воздействием занятий футболом // Естественные науки. Издательство: Федеральное государственное бюджетное образовательное учреждение высшего профессионального образования «Астраханский государственный университет». 2016. № 1 (54). С. 82-88. 